\title{
Reseña
}

\section{Psicoanálisis y Feminismos. Reseña de una apuesta a la extensión}

\author{
Luciana Szrank*
}

Universidad Nacional de Córdoba

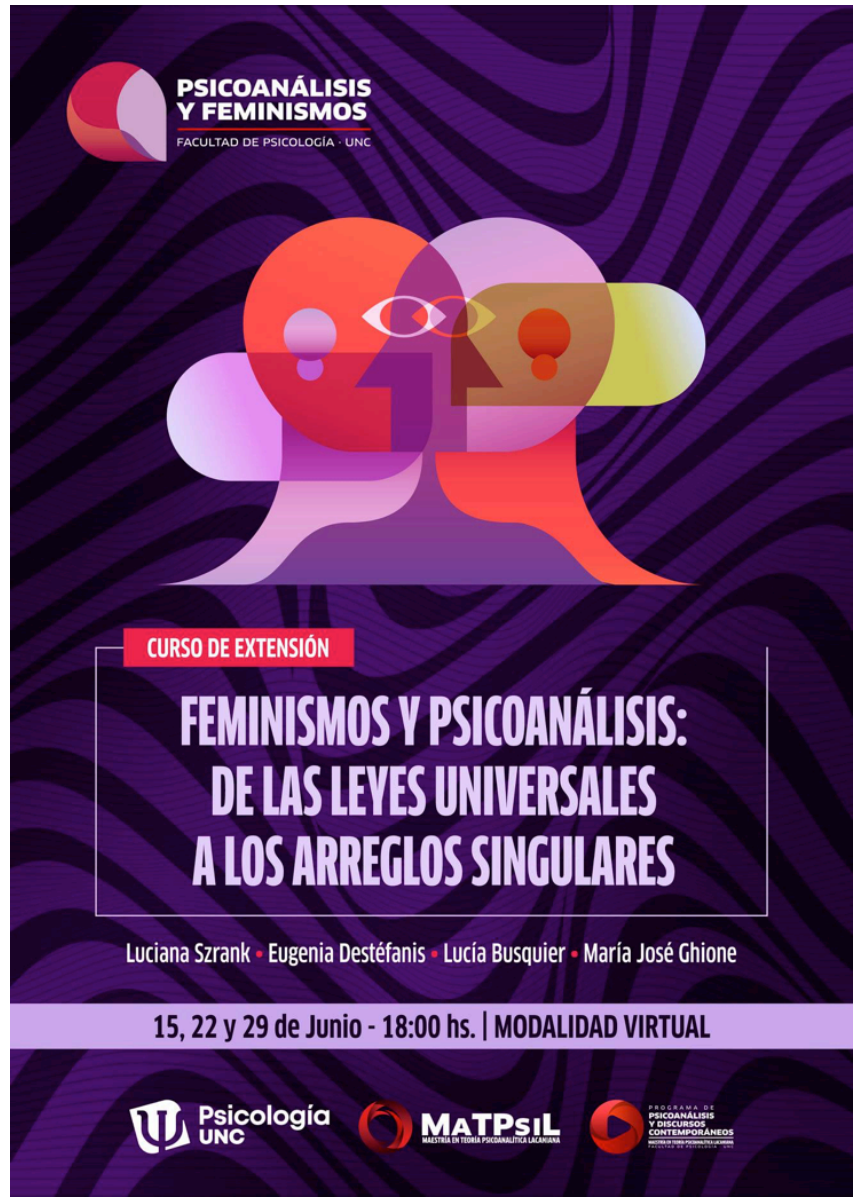

Un curso de extensión universitaria como apuesta de salida, de la universidad a la comunidad, del psicoanálisis a la ciudad.

Con Eugenia Destéfanis, Lucía Busquier, María José Ghione y por supuesto, también con la orientación del equipo de trabajo de la Maestría en Teoría Psicoanalítica Lacaniana, de la Facultad de Psicología de la U.N.C. y su programa de extensión Psicoanálisis y discursos contemporáneros, nos propusimos impulsar un espacio de conversación entre el psicoanálisis y los feminismos, por la vía de un curso de extensión titulado Feminismos y psicoanálisis: de las leyes universales a los arreglos singulares. Estuvo dividido en tres encuentros, contando cada uno con un título que orientó las discusiones: “¿Qué moral sexual cultural hoy?”, "El universal mujer y sus efectos segregativos" y "Lo que la ley no alcanza".

El primero contó con la presencia de tres invitados, Alejandro Willington - psicoanalista, miembro de la EOL (Escuela de la Orientación Lacaniana)-, Sofía Zurbriggen y Eduardo Mattio, - provenientes del campo de la filosofía, la investigación y la docencia, rela-

* lucianaszrank@gmail.com 
cionados ambos a su vez a los activismos feministas-. Se dio allí un espacio de discusión y lectura de distintas aristas de la moral sexual cultural de nuestra época, pensando en las implicancias y derivas de leyes vigentes en nuestro país, como la de Educación Sexual Integral y la de Interrupción Voluntaria del Embarazo. Por su parte, Sofía Zurbriggen, compartió parte de la investigación que se encuentra realizando en relación a las respuestas que vienen dando hace tiempo una organización de socorristas - activistas feministas que acompañan a personas en procesos de interrupción voluntaria de embarazos-, destacando la importancia, en el momento actual, de diferenciar lo legal, de la legalidad de las prácticas, así como el sentido que se introduce en las prácticas y su posibilidad de resignificación. Señaló también la centralidad de la idea de "representación del poder heterárquica", es decir como eso que habla de cierta independencia de acción en lo micro, respecto a un sistema macro establecido, jerarquizado, normalizado. También allí, Eduardo Mattio destacó cómo la ley de E. S. I., como dispositivo tanto pedagógico como de subjetivación ha tenido diversas respuestas - desde resistencias o usos confesionales de algunos actores hasta subversiones críticas por parte de otros-y que en relación a ello podemos preguntarnos qué aspectos de la moral sexual compartida se han conmovido y se habrán de conmover en el proceso de aplicación de este dispositivo, invitando a resaltar que la lógica de los arreglos singulares puede sumar a los agenciamientos colectivos en tanto y en cuanto no se confundan con la vía de sali$\mathrm{da}$ individualista que promueve el capitalismo, es decir apelando a una implicación, a una respuesta responsable por parte de las singularidades con el Otro social. Por su parte, Alejandro Willington resaltó la importancia de seguir recordando en la actualidad el acontecimiento Freud, que implicó y aun hoy implica una subversión del pensamiento tradicional sobre la sexualidad - por destacar por ejemplo, su carácter inevitablemente polimorfo-. Esto posibilita una ampliación de lectura, ante lo acotada y segregativa que es la lectura realizada por parte de discursos conservadores vigentes aun hoy, por ejemplo ciertos actores del discurso médico, que defienden una idea de normalidad en relación a la sexualidad y por consecuencia, una continuidad en la deriva de la patologización. Por mi parte, en este mismo encuentro me propuse transmitir una lectura, una perspectiva en torno a la "diferencia" de la que se trata en el psicoanálisis, esa absolutamente única de cada quien que habla - ni genérica, ni generalizable-, que refiere a cómo un ser hablante y su cuerpo es afectado por el hecho de habitar un mundo de lenguaje y de cómo en cada cuerpo las experiencias de goce inolvidables, acontecen, marcan y se cuentan, de manera única e irrepetible. Siempre por ende, cada caso excede a su manera a la lógica del "para todos igual" que inevitablemente establecen las leyes y sus protocolos públicos de acción.

La segunda conversación arrancó a tres voces, dos de practicantes del psicoanálisis y una proveniente del campo de la historia. Lucía Busquier, es la historiadora que con su pragmática discursiva supo transmitir a partir de sus investigaciones, diferentes invenciones - es decir ejemplos de luchas, coaliciones, resistencias, experiencias artísticas-, que se constituyen como herramientas y prácticas políticas concretas de un sector del activismo y la academia feminista, el de las mujeres afrodescendientes. Destacando la necesidad de llevar adelante prácticas descolonizadoras, las voces y acciones de estas mujeres - que han sido múltiplemente segregadas a lo largo de la historia - han sabido discutir y objetar las pretensiones de universalidad puestas sobre el sujeto mujer.

Eugenia Destéfanis, recuperó perlas freudianas que no conviene olvidar a la hora de leer lo que sucede en la humanidad. Por un lado, en relación a lo eficaz que es la pulsión de muerte y por otro, a lo complejo que es el cumplimiento del mandato del amor al prójimo entre los seres hablantes. Se encargó también de transmitir cómo lo universal nos lleva a hablar de segregación y cómo el psicoanálisis desde siempre se ocupó y preocupó por ello, destacándose justamente por ser un discurso que tiene en cuenta la dimensión del goce - existente en los seres/cuerpos hablantes como imposible de universalizar - y que opera de manera antisegregativa. Por su parte, Liliana Aguilar (miembro de la EOL) pudo hacer pasar la diferencia que existe entre la lógica de lo universal -que conlleva efectos segregativos- y la lógica de lo femenino, - que viene más bien a vetar lo universal-, caracterizándose por corresponder a una lógica que incluye las experiencias de goce que refieren al enigma, a la alteridad propia al ser hablante. Destacó y aclaró también, lo que implica lo femenino para el psicoanálisis, como eso que está absolutamente fuera de género no refiriendo por ende a identificaciones - ya que justamente no tiene que ver con el decir, con las palabras sino más bien con letras de goce, con experiencias de goce en los cuerpos.

La tercera interlocución contó con la participación de tres practicantes del psicoanálisis: Matías Meichtri Quintans (miembro de la EOL), Agustina Brandi 
y María José Ghione, y con investigadoras y activistas feministas provenientes de distintas áreas de intervención: Denise Paz Ruíz, del Trabajo Social y Guillermina Huarte, de la Comunicación Social. Maria José Ghione, por su parte realizó una puntación del recorrido del curso y retomó aportes fundamentales del psicoanálisis para entender lo inevitable del malestar en la cultura. Agustina Brandi, continuó la línea de conversación haciendo hincapié en cómo las leyes - que operan por la lógica de lo universal - conllevan un efecto de negación de lo irreductible en lo humano, y en cómo este taponamiento de la dimensión de lo imposible tiene efectos de retorno en lo social. Especificó que, cada quien ha de dar su consentimiento a la ley y que lo que se tiene en cuenta desde el psicoanálisis es ese arreglo singular que se pone allí en juego. Por su parte, Matías Meichtri Quintans puso énfasis en la necesidad de que se den estas conversaciones y destacó que, si aún tomamos a Freud es porque nos sirve para pensar lo que nos pasa tanto individual como colectivamente. Introdujo a su vez en la conversación, la inevitable transacción que la vida en sociedad implica, donde hemos de renunciar a algo de la satisfacción de nuestras pulsiones para así poder regular el malestar entre todos. Recordó también algo fundamental a tener en cuenta, sobre lo insuficiente que resulta pensar la violencia meramente en relación al aparato normativo. Denise Paz Ruíz, quien tiene experiencia de intervención e investigación en el ámbito de la violencia contra las mujeres, destacó que sería un error pensar la reparación en un sentido de "para todos igual”, por ser esta justamente más bien de orden absolutamente singular. Por otro lado, señaló que los paradigmas securitistas son un índice de la época neoliberal e hizo énfasis en la necesidad de que exista una justicia no burocrática, esa que permite sostener la dignidad del acto de justicia. Por su parte, Guillermina Huarte, como comunicadora, introdujo en la conversación interesantes preguntas y críticas en relación a la "razón punitiva" que circula en nuestra actualidad: ¿hay formas alternativas al código penal?, ¿cualquier práctica es escrachable?, ¿qué sucede cuando se demanda más y más seguridad, más y más vigilancia? ¿hasta qué punto las cosas son reparables? Como activista feminista, defendió también la idea de que siempre en el "movimiento", se cuenta con la posibilidad de revisar aquello que se haya propuesto.

Además del recorrido propuesto por quienes hemos sido docentes del curso, cada encuentro fue sumamente enriquecido por los aportes y preguntas de las personas que ingresaron y participaron con entusiasmo en las sucesivas conversaciones. En resumen, vivimos una experiencia de salida y de cruce, entre discursos y entre personas sumamente diversas provenientes de distintos campos de acción y formación, pero movidos por un interés en común, seguir pensando los conceptos, las ideas y las acciones - como seres hablantes y como profesionales - que resulten convenientes para la lectura y el abordaje de procesos de transformación social y/o ante la presencia de dificultades con el Otro social y/o con el Otro corporal. Nos quedan valiosas preguntas para continuar poniéndonos al trabajo de conversar. 